Research Paper

\title{
Survival benefit of adjuvant chemotherapy for patients with poorly differentiated stage IIA colon cancer
}

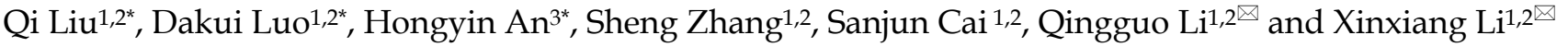 \\ 1. Department of Colorectal Surgery, Fudan University Shanghai Cancer Center, Shanghai, China. \\ 2. Department of Oncology, Shanghai Medical College, Fudan University, Shanghai, China. \\ 3. Department of General Surgery, the First People's Hospital of Yancheng, Yancheng, China. \\ * These authors contributed equally to this work.
}

$\triangle$ Corresponding author: Xinxiang Li MD, PhD, Department of Colorectal Surgery, Fudan University Shanghai Cancer Center, \#270 Dongan Road, Xuhui District, Shanghai, China, Postal code: 200032, E-mail: 11491xx@sina.com; Qingguo Li MD, PhD, Department of Colorectal Surgery, Fudan University Shanghai Cancer Center, \#270 Dongan Road, Xuhui District, Shanghai, China, Postal code: 200032, E-mail: oncosurgeonli@sohu.com

(1) Ivyspring International Publisher. This is an open access article distributed under the terms of the Creative Commons Attribution (CC BY-NC) license (https://creativecommons.org/licenses/by-nc/4.0/). See http://ivyspring.com/terms for full terms and conditions.

Received: 2018.08.01; Accepted: 2018.12.27; Published: 2019.01.29

\begin{abstract}
Background: The effect of adjuvant chemotherapy on stage II colon cancer remains constantly controversial. Recently, however, several studies have reported the definite survival benefit of adjuvant chemotherapy (ACT) in T4 disease (stage IIB and IIC) among stage II colon cancer patients. The following study investigates the efficacy of ACT in patients with poorly differentiated stage IIA colon cancer.

Methods: The first cohort of eligible patients $(\mathrm{N}=38384)$ diagnosed with stage IIA colon cancer was selected from the Surveillance, Epidemiology, and End Results database (SEER) between January 1, 2004, and December 31, 2010. Cox proportional hazards regression analyses and Kaplan-Meier curves were used to evaluate the survival benefit following ACT. Our findings were also evaluated in Fudan University Shanghai Cancer Center (FUSCC) cohort form FUSCC database.

Results: In SEER cohort, poorly differentiated or undifferentiated tumor grade was associated with $21.5 \%$ increased cancer-specific mortality in patients who did not receive ACT $(H R=1.215,1.004-1.469, P=0.045$, using poorly differentiated or undifferentiated ACT as a reference). In FUSCC cohort, poorly differentiated or undifferentiated tumor grade was also associated with increased DFS in patients who received ACT $(H R=$ $0.160,95 \% \mathrm{Cl}=0.017-1.505, \mathrm{P}=0.109$, using poorly differentiated or undifferentiated, non- $\mathrm{ACT}$ as a reference). In addition, patients with poorly differentiated or undifferentiated tumor who did not receive ACT had a higher risk of distant metastasis and recurrence compared to patients who received ACT (log-rank $P=0.027$ and 0.119 , respectively).

Conclusion: ACT decreased the recurrence rate and distant metastasis rate thus improving prognosis for poorly differentiated or undifferentiated stage IIA colon cancer.
\end{abstract}

Key words: adjuvant chemotherapy; tumor grade; stage IIA colon cancer

\section{Introduction}

Colorectal cancer is one of the most commonly diagnosed cancers in men and women [1]. Patients with stage II disease account for approximately $30-40 \%$ of colorectal cancer patients [2, 3]. Although adjuvant chemotherapy (ACT) is widely accepted as standard treatment for patients with stage III colon cancer, its role in stage II colon cancer remains controversial [4-6].

Even though there is a lack of evidence regarding the efficiency of ACT for stage II colon cancer patients, the American Society of Clinical Oncology (ASCO) clinical guidelines recommend the use of ACT for cases with so-called high-risk factors (including patients with inadequately sampled nodes, T4 lesions, perforation, or poorly differentiated histology) [7]. Also, similar recommendations have been suggested by the European Society for Medical Oncology (ESMO) [8].

The conclusions about the efficacy of adjuvant CT among high-risk stage II colon cancer are not 
consistent [9-15]. Data from two recent studies have suggested that ACT is not suitable for stage II colon cancer patients with poorly/undifferentiated tumor $[10,11]$. In 2018, a randomized-controlled trial (RCT) called SACURA was performed with the purpose of examining the effect of ACT in stage II colon cancer; the study reported that patients with poorly differentiated histology, which was listed as one of "high-risk" factors, did not benefit from ACT or had any impact on the relapse-free survival in stage II colon cancer [13]. Recently, however, several studies have reported the definite survival benefit of ACT in T4 disease (stage IIB and IIC) among stage II colon cancer patients $[10,15,16]$. Consequently, the aim of this study was to investigate the effect of ACT on tumor grade and survival benefit in stage IIA colon cancer patients.

\section{Patients and Methods}

\subsection{Patient Selection from SEER database}

The Surveillance, Epidemiology, and End Results (SEER) Program of the United States National Cancer Institute is an authoritative source which collects patient demographic information, cancer diagnostic information, and outcomes from 18 cancer registries in the United States, thus including approximately $28 \%$ of the US population. In this study, the first cohort we used was from the SEER

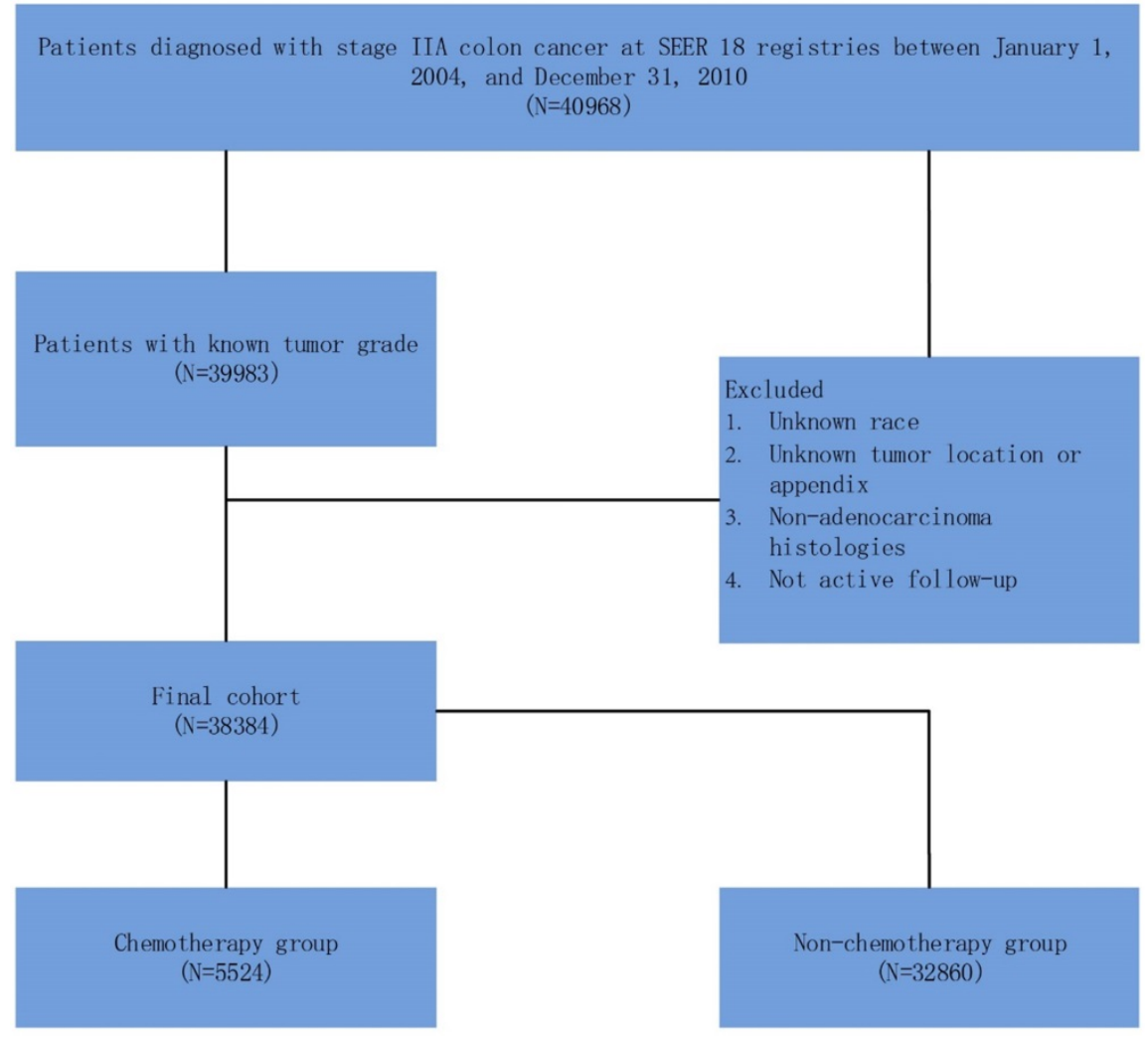

Figure 1. Schematic representation of patient population selected from SEER database. database. The SEER database does not contain any identifiers and is publicly available for the studies of cancer-based epidemiology. In the present study, the National Cancer Institute's SEER-Stat software (version 8.3.5) was used to get access to SEER database.

As shown in Figure 1, 40968 patients, diagnosed with stage IIA (T3NOM0) colon cancer between January 1, 2004 and December 31, 2010, were identified. Patients with unknown tumor grade were excluded from the study. Other exclusion criteria were: unknown race; unknown tumor location or appendix; non-adenocarcinoma histology and not active follow-up.

In this study, we stratified the "patient had chemotherapy" as ACT group and "no evidence of chemotherapy was found in the medical records examined" as a non-ACT group in the variable "chemotherapy recode" in SEER cohort. The primary endpoint in SEER cohort was cause-specific survival (CSS). The cause of death was categorized as colon cancer specific or non-colon cancer related. The CSS was calculated from the date of diagnosis to the date of colon cancer death. Patients who died of other causes were censored at the date of death. Well, moderately, poorly, and undifferentiated tumor grade accounted for $7.9 \%(\mathrm{n}=3035), 74.9 \% \quad(\mathrm{n}=28756), 15.8 \%$ $(n=6080)$ and $1.3 \% \quad(n=513)$ of the whole cohort, respectively. Then we combined well and moderately tumor grade which were traditionally associated with better prognosis as the same group, poorly and undifferentiated tumor grade as the other group.

\subsection{Patient Selection from FUSCC database}

As shown in Supplementary Figure, patients $(\mathrm{N}=237)$ diagnosed with stage IIA colon cancer of the validation cohort were selected between January 1 , 2008 and December 31, 2015 from the FUSCC. The study was approved by the Ethical Committee and Institutional Review Board of FUSCC. All patients were identified by pathological examination after operation, and patients with incomplete relevant data, such as active follow-up information, TNM stage, tumor grade, tumor location, histology, tumor size, 
and chemotherapy information, were excluded from the study. The outcomes of interest were disease-free survival (DFS), relapse-free survival (RFS) and distant metastasis-free survival (DMFS), which were calculated from the date of diagnosis to the date of first event of recurrence, distant metastasis or death.

\subsection{Statistical analyses}

In this study, we compared different clinicopathologic factors between the ACT and non-ACT groups using Pearson's chi-squared test for different variables. Several multivariate Cox proportional hazard models were constructed to identify the survival benefit of ACT. To determine whether there was a significant interaction between tumor grade and ACT in predicting CSS, we defined a variable combined with tumor grade and ACT. Survival curves were constructed using the Kaplan-Meier method, and univariate survival difference was determined with the log-rank test. Statistical analysis was mainly performed with SPSS version 22 (SPSS Inc., Chicago IL); and two-sided $P<0.05$ was considered statistically significant.

For the SEER cohort, well and moderately differentiated tumor grades were considered as one group, poorly differentiated and undifferentiated tumor grades as another group. Multivariate Cox proportional hazard models were used to test for differences in CSS after controlling for histology, race, gender, tumor location, year of diagnosis, tumor size and age at diagnosis. Pair-wise comparisons were performed between different combinations of tumor grade and ACT to determine the presence of significant CSS differences.

For the FUSCC cohort, well differentiated, well-moderately differentiated and well-moderately differentiated tumor grade were considered as one group, and poorly-moderately differentiated, poorly differentiated, and undifferentiated tumor grade as another group. Multivariate Cox proportional hazard models were used to test for differences in CSS after controlling for tumor location, age at diagnosis, year of diagnosis, gender, neoadjuvant chemotherapy, histology and tumor size.

\section{Results}

\subsection{Patient characteristics of the SEER and FUSCC cohorts}

A total of 38384 stage IIA colon cancer patients were identified from SEER database. A median follow-up time was 74 months and 4913 (12.8\%) patients died of colon cancer at the end of the follow-up. In the SEER cohort, 32860 patients (85.6\%) were stratified into the non-ACT group, and 5524
(14.4\%) into the CT group. The patients' baseline demographic characteristics are shown in Table $\mathbf{1}$. White, female, with proximal colon, later diagnosis, small tumor size, old age and well/moderately differentiated were more likely to receive ACT in stage IIA colon cancer (Table 1, $\mathrm{P}<0.05$ ).

Table 1. Comparison of baseline characteristics by the receipt of $A C T$ in SEER cohort

\begin{tabular}{|c|c|c|c|}
\hline \multirow[t]{2}{*}{ Variable } & \multicolumn{2}{|c|}{ No. of Patients (\%) } & \multirow[t]{2}{*}{$P$} \\
\hline & $\operatorname{ACT}(n=12382)$ & Non-ACT $(n=61015)$ & \\
\hline Histology & & & 0.164 \\
\hline Adenocarcinoma & $29496(89.8)$ & $4945(89.5)$ & \\
\hline Mucinous adenocarcinoma & $3173(9.7)$ & $535(9.7)$ & \\
\hline Signet ring cell carcinoma & $191(0.6)$ & $44(0.8)$ & \\
\hline Race & & & 0.002 \\
\hline White & $27163(82.7)$ & $4459(80.7)$ & \\
\hline Black & $3454(10.5)$ & $654(11.8)$ & \\
\hline Other & $2243(6.8)$ & $411(7.4)$ & \\
\hline Gender & & & $<0.001$ \\
\hline Male & $15706(47.8)$ & $2845(51.5)$ & \\
\hline Female & $17154(52.2)$ & $2679(48.5)$ & \\
\hline Tumor location & & & $<0.001$ \\
\hline Cecum & $7685(23.4)$ & $1098(19.9)$ & \\
\hline Ascending colon & $8099(24.6)$ & $1062(19.2)$ & \\
\hline Hepatic flexure & $2225(6.8)$ & $328(5.9)$ & \\
\hline Transverse colon & $3964(12.1)$ & $633(11.5)$ & \\
\hline Splenic flexure & $1383(4.2)$ & $274(5.0)$ & \\
\hline Descending colon & $2030(6.2)$ & $414(7.5)$ & \\
\hline Sigmoid Colon & $7474(22.7)$ & $1715(31.0)$ & \\
\hline Year of diagnosis & & & $<0.001$ \\
\hline 2004-2007 & $19102(58.1)$ & $3537(64.0)$ & \\
\hline 2008-2010 & $13758(41.9)$ & $1987(36.0)$ & \\
\hline Tumor size $(\mathrm{cm})$ & & & $<0.001$ \\
\hline$\leq 4$ & $13395(40.8)$ & $1971(35.7)$ & \\
\hline$>4$ & $18282(55.6)$ & $3317(60.0)$ & \\
\hline Unknown & $1183(3.6)$ & $236(4.3)$ & \\
\hline Age at diagnosis (y) & & & $<0.001$ \\
\hline$\leq 70$ & $12158(37.0)$ & $4256(77.0)$ & \\
\hline$>70$ & $30702(63.0)$ & $1268(23.0)$ & \\
\hline Tumor grade & & & $<0.001$ \\
\hline Well/moderately differentiated & $27384(93.3)$ & $4407(79.8)$ & \\
\hline $\begin{array}{l}\text { Poorly differentiated or } \\
\text { undifferentiated }\end{array}$ & $5476(16.7)$ & $1117(20.2)$ & \\
\hline
\end{tabular}

Totally, 237 stage IIA colon cancer patients were identified from FUSCC database. A median follow-up time was 37 months among censored patients. In the FUSCC cohort, 125 patients $(52.7 \%)$ were stratified into the non-ACT group, and 112 (47.3\%) into the CT group. The patients' baseline demographic characteristics are shown in Supplementary Table 1.

\subsection{Associations of CCS benefit offered by ACT in SEER database}

In the multivariate Cox analysis, a significant interaction was found between tumor grade and ACT in determining CSS ( $\mathrm{P}=0.007$, Table 2). Well/moderately differentiated tumor grade was not associated with statistically different survival benefit in patients who received $\mathrm{ACT} \quad(\mathrm{HR}=0.977,95 \%$ $\mathrm{CI}=0.890-1.073, \quad \mathrm{P}=0.628$, using well/moderately differentiated, using non-ACT as a reference). Yet, poorly differentiated or undifferentiated tumor grade 
was associated with $21.5 \%$ increased cancer-specific mortality in patients who did not receive ACT $(\mathrm{HR}=1.215$, 1.004-1.469, $\mathrm{P}=0.045$, using poorly differentiated or undifferentiated ACT as a reference) compared with those who did. As shown in Table 2, histological data, race, tumor location, year of diagnosis, tumor size and age at diagnosis were independent prognostic factors in stage IIA colon cancer.

Table 2. Multivariate Cox regression analyses of CSS in SEER cohort

\begin{tabular}{|c|c|c|c|c|}
\hline \multirow[t]{2}{*}{ Variable } & \multicolumn{2}{|l|}{ Overall } & \multicolumn{2}{|l|}{ Pairwise } \\
\hline & HR $(95 \% \mathrm{CI})$ & $P$ & HR $(95 \% \mathrm{CI})$ & $P$ \\
\hline Histology & & 0.022 & $\ldots$ & $\ldots$ \\
\hline Adenocarcinoma & Reference & & & \\
\hline $\begin{array}{l}\text { Mucinous } \\
\text { adenocarcinoma }\end{array}$ & $0.886(0.801-0.981)$ & 0.020 & & \\
\hline $\begin{array}{l}\text { Signet ring cell } \\
\text { carcinoma }\end{array}$ & $0.710(0.461-1.095)$ & 0.121 & & \\
\hline Race & & $<0.001$ & $\ldots$ & $\ldots$ \\
\hline White & Reference & & & \\
\hline Black & $1.461(1.345-1.587)$ & $<0.001$ & & \\
\hline Other & $0.885(0.787-0.995)$ & 0.040 & & \\
\hline Gender & & $<0.001$ & $\ldots$ & $\ldots$ \\
\hline Male & Reference & & & \\
\hline Female & $0.897(0.848-0.950)$ & & & \\
\hline Tumor location & & $<0.001$ & $\ldots$ & $\ldots$ \\
\hline Cecum & Reference & & & \\
\hline Ascending colon & $0.890(0.817-0.969)$ & 0.007 & & \\
\hline Hepatic flexure & $0.914(0.803-1.041)$ & 0.175 & & \\
\hline Transverse colon & $0.987(0.890-1.094)$ & 0.799 & & \\
\hline Splenic flexure & $1.242(1.081-0.427)$ & 0.002 & & \\
\hline Descending colon & $1.186(1.050-1.340)$ & 0.006 & & \\
\hline Sigmoid Colon & 1.295 (1.195-1.405) & $<0.001$ & & \\
\hline Year of diagnosis & & 0.020 & $\ldots$ & $\ldots$ \\
\hline 2004-2007 & Reference & & & \\
\hline 2008-2010 & $0.932(0.878-0.989)$ & & & \\
\hline Tumor size $(\mathrm{cm})$ & & 0.019 & $\ldots$ & $\ldots$ \\
\hline$\leq 4$ & Reference & & & \\
\hline$>4$ & 1.069 (1.008-1.134) & 0.027 & & \\
\hline Unknown & $1.176(1.018-1.358)$ & 0.028 & & \\
\hline Age at diagnosis $(y)$ & & $<0.001$ & $\ldots$ & $\ldots$ \\
\hline$\leq 70$ & Reference & & & \\
\hline$>70$ & 1.834 (1.723-1.951) & & & \\
\hline Tumor grade and ACT & & 0.007 & $\ldots$ & $\ldots$ \\
\hline $\begin{array}{l}\text { Well/moderately } \\
\text { differentiated, } \\
\text { non-ACT }\end{array}$ & Reference & & $1.064(0.889-1.273)$ & 0.501 \\
\hline $\begin{array}{l}\text { Well/moderately } \\
\text { differentiated, ACT }\end{array}$ & $0.977(0.890-1.073)$ & 0.628 & $1.039(0.856-1.262)$ & 0.697 \\
\hline $\begin{array}{l}\text { Poorly differentiated } \\
\text { or undifferentiated, } \\
\text { non-ACT }\end{array}$ & $1.142(0.890-1.073)$ & 0.001 & 1.215 (1.004-1.469) & 0.045 \\
\hline $\begin{array}{l}\text { Poorly differentiated } \\
\text { or undifferentiated, } \\
\text { ACT }\end{array}$ & $0.940(0.786-1.125)$ & 0.501 & Reference & \\
\hline
\end{tabular}

\subsection{Evaluating the SEER outcomes in the FUSCC cohort}

SEER database did not provide some information such as tumor recurrence and distant metastasis, so these findings in SEER should be treated with caution. We evaluated the above findings in 237 stage IIA colon cancer identified from the FUSCC cohort. Results of multivariate Cox analyses showed that well/moderately differentiated was associated with the similar DFS in patients who received ACT $(\mathrm{HR}=0.959,95 \% \mathrm{CI}=0.358-2.571$, $\mathrm{P}=0.933$, using well/moderately differentiated, non-ACT as a reference) (Table 3). However, poorly differentiated or undifferentiated tumor grade was associated with an increase in DFS after receiving ACT $(\mathrm{HR}=1.311,95 \% \mathrm{CI}=0.389-4.415, \mathrm{P}=0.662$ for poorly differentiated or undifferentiated; non-ACT, $\mathrm{HR}=0.210$, 95\% $\mathrm{CI}=0.024-1.834, \mathrm{P}=0.158$ for poorly differentiated or undifferentiated, ACT, using well/moderately differentiated, non-ACT as a reference).

Table 3. Multivariate Cox regression analyses of CSS in FUSCC cohort.

\begin{tabular}{|c|c|c|c|c|}
\hline \multirow[t]{2}{*}{ Variable } & \multicolumn{2}{|c|}{ Cancer-specific survival } & \multicolumn{2}{|l|}{ Pairwise } \\
\hline & HR (95\%) & $P$ & HR(95\%CI) & $P$ \\
\hline Tumor location & & 0.982 & $\cdots$ & $\cdots$ \\
\hline Right colon & Reference & & & \\
\hline Transverse colon & $0.810(0.169-3.877)$ & 0.792 & & \\
\hline Left colon & $1.035(0.278-3.861)$ & 0.959 & & \\
\hline Sigmoid colon & $0.836(0.296-2.358)$ & 0.734 & & \\
\hline Age (years) & & 0.415 & $\cdots$ & $\ldots$ \\
\hline$\leq 70$ & Reference & & & \\
\hline$>70$ & $1.526(0.552-4.219)$ & & & \\
\hline Year of diagnosis & & 0.171 & $\cdots$ & $\ldots$ \\
\hline 2008-2011 & Reference & & & \\
\hline 2012-2015 & $0.513(0.198-1.332)$ & & & \\
\hline Gender & & 0.745 & $\cdots$ & $\ldots$ \\
\hline Male & Reference & & & \\
\hline Female & $1.156(0.482-2.772)$ & & & \\
\hline $\begin{array}{l}\text { Neoadjuvant } \\
\text { chemotherapy }\end{array}$ & & 0.727 & $\cdots$ & $\cdots$ \\
\hline No & Reference & & & \\
\hline Yes & $\begin{array}{c}1.479 \\
(0.165-13.260)\end{array}$ & & & \\
\hline Histology & & 0.454 & $\ldots$ & $\ldots$ \\
\hline Adenocarcinoma & Reference & & & \\
\hline $\begin{array}{c}\text { Mucinous } \\
\text { adenocarcinoma/ signet } \\
\text { ring cell carcinoma }\end{array}$ & $1.480(0.530-4.131)$ & & & \\
\hline Tumor size (cm) & & 0.699 & $\ldots$ & $\ldots$ \\
\hline$\leq 4$ & Reference & & & \\
\hline$>4$ & $1.206(0.466-3.123)$ & & & \\
\hline Tumor grade and ACT & & 0.461 & $\cdots$ & $\ldots$ \\
\hline $\begin{array}{c}\text { Well/moderately } \\
\text { differentiated }{ }^{*} \text {, non-ACT }\end{array}$ & Reference & & $0.763(0.227-2.569)$ & 0.662 \\
\hline $\begin{array}{l}\text { Well/moderately } \\
\text { differentiated", ACT }\end{array}$ & $0.959(0.358-2.571)$ & 0.933 & $0.731(0.209-2.556)$ & 0.624 \\
\hline $\begin{array}{l}\text { Poorly differentiated or } \\
\text { undifferentiated } \\
\text { non-ACT }\end{array}$ & $1.311(0.389-4.415)$ & 0.662 & Reference & \\
\hline $\begin{array}{l}\text { Poorly differentiated or } \\
\text { undifferentiated", ACT }\end{array}$ & $0.210(0.024-1.834)$ & 0.158 & $0.160(0.017-1.505)$ & 0.109 \\
\hline $\begin{array}{l}\text { Abbreviation: FUSCC, Fu } \\
\text { chemotherapy }\end{array}$ & Idan University Sha & ghai & cer Center; ACT, a & \\
\hline $\begin{array}{l}\text { Well/moderately differen } \\
\text { differentiated and well-m } \\
\text { undifferentiated } \\
\text { diffincludi } \\
\text { differentiated, and undiff }\end{array}$ & $\begin{array}{l}\text { tiated*: including w } \\
\text { oderately differentia } \\
\text { ng poorly-moderate } \\
\text { erentiated }\end{array}$ & $\begin{array}{l}\text { ell diffe } \\
\text { ted Po } \\
\text { ly diffe }\end{array}$ & $\begin{array}{l}\text { entiated, well-moder } \\
\text { ly differentiated or } \\
\text { ntiated poorly }\end{array}$ & \\
\hline
\end{tabular}

Next, we investigated the relapse and metastasis patterns of tumor grade with or without receiving ACT. As shown in Figure 2, patients who did not receive ACT and were diagnosed with well/moderately differentiated tumor grade had 
similar DMFS rates compared to those who received ACT (log-rank $P=0.916)$. Nevertheless, patients with poorly differentiated or undifferentiated tumor without receiving ACT had an increased risk of distant metastasis compared with those who received ACT (log-rank $\mathrm{P}=0.027$ ). Poorly differentiated or undifferentiated tumor grade presented no cases of distant metastasis after receiving ACT, this might be due to the small sample size $(n=33)$ and relatively short median follow-up time ( $\mathrm{n}=37$ months) of poorly differentiated or undifferentiated, ACT. As shown in Figure 3, we found similar RFSs in patients with well/moderately differentiated who received ACT and those who did not receive ACT (log-rank $\mathrm{P}=0.580$ ). In addition, patients with poorly differentiated or undifferentiated tumor grade had a relatively lower risk of tumor recurrence after receiving ACT compared to patients who did not receive ACT; nonetheless, the difference was not significant (log-rank $\mathrm{P}=0.119$ ), which was probably due to the small sample size and relatively short follow-up time. The Cox analyses after adjustment showed the similar results (Supplementary Table 2).

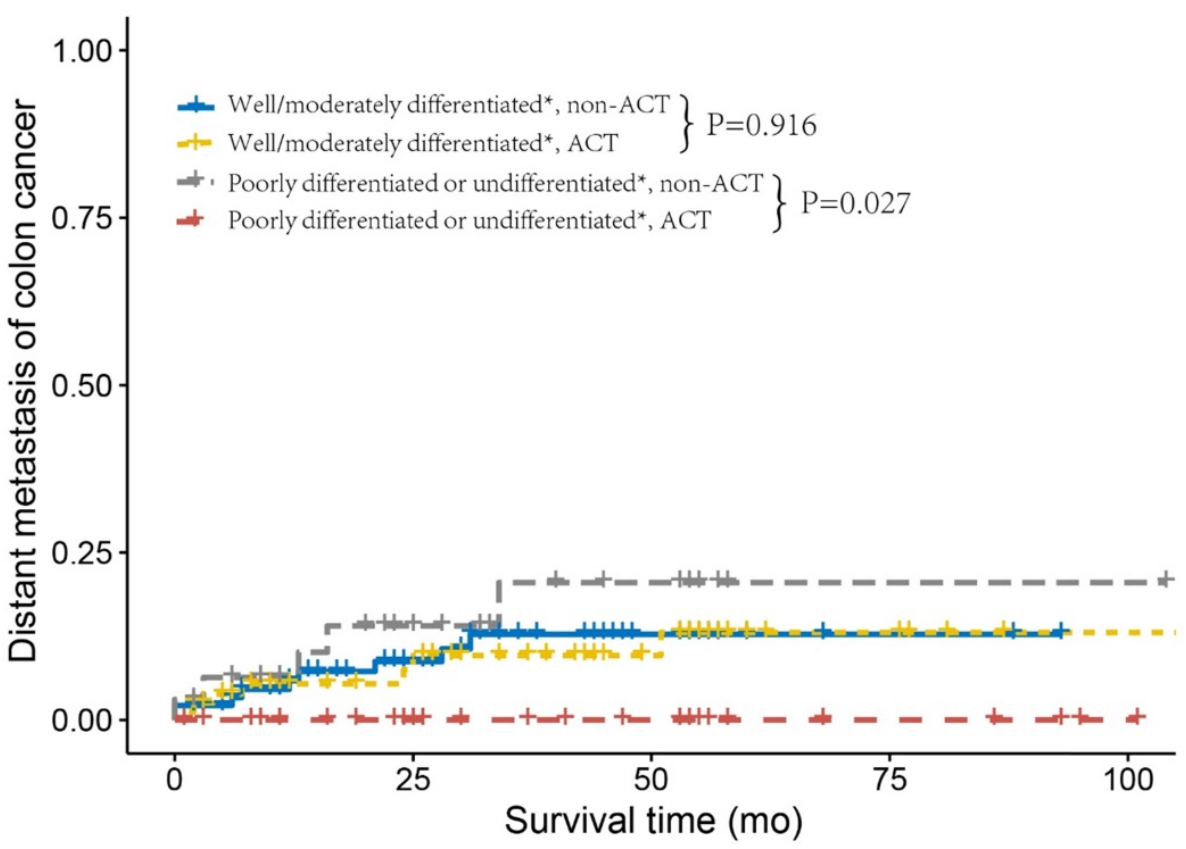

Figure 2. Distant metastasis curves using the Kaplan-Meier method in stage IIA colon cancer from the Fudan University Shanghai Cancer Center (FUSCC).

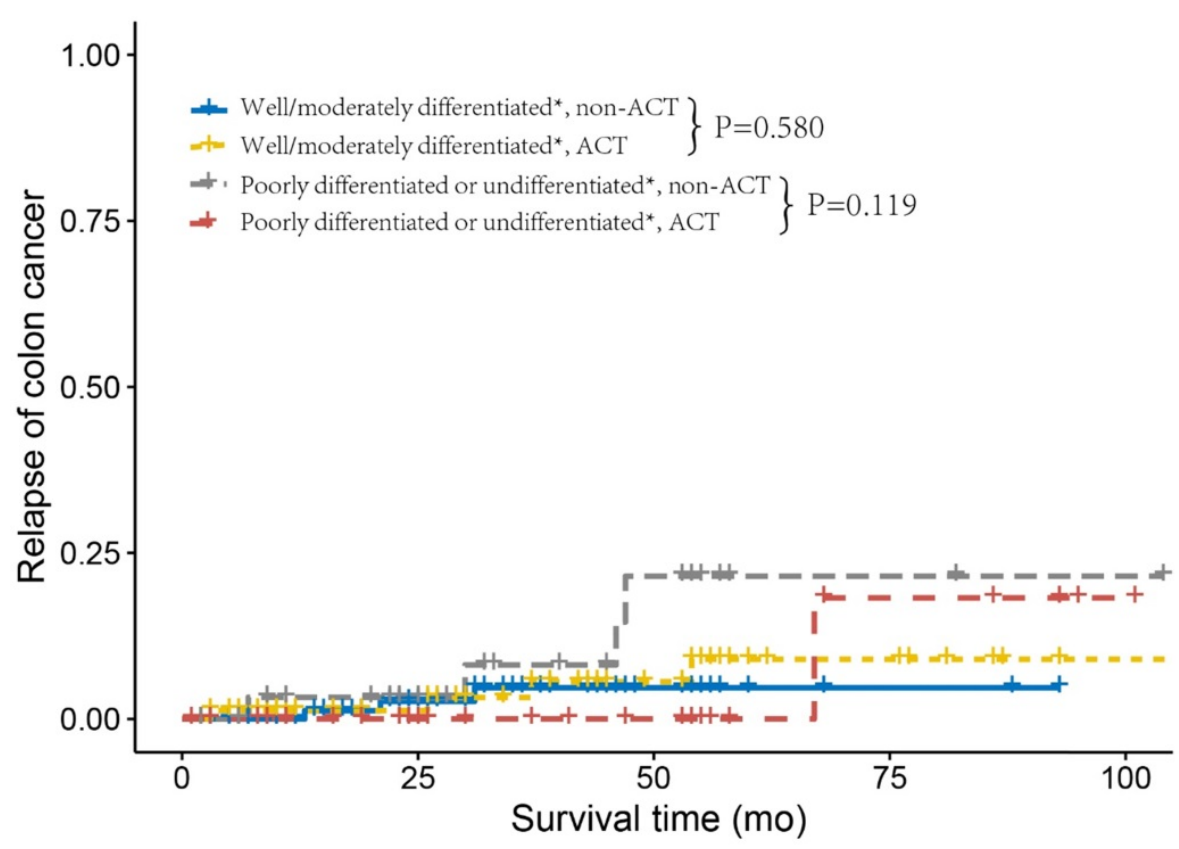

Figure 3. Relapse curves using the Kaplan-Meier method in stage IIA colon cancer from the Fudan University Shanghai Cancer Center (FUSCC). 


\section{Discussion}

In today's clinical practice, ACT is widely used to treat stage II colon cancer with high-risk factors without enough of direct evidence [7,8]. Due to the possibility of excessive treatment or undertreatment, survival benefits of ACT in high-risk stage II colon cancer have been addressed by number of studies; nevertheless, the obtained conclusions have been largely inconsistent [10-13, 17].

Recent studies have shown absolute efficacy of ACT in stage IIB and IIC colon cancer. In 2014, Aalok and his colleges reported that the recurrence-free survival (RFS), disease-specific survival (DSS), and overall survival (OS) benefit of adjuvant CT was mainly observed in patients with T4 disease [16]. Two later studies from the USA and Netherlands confirmed these same findings, thus proving that the maximum survival benefit in T4 could be obtained with adjuvant therapy $[10,15]$.

Although stage IIA colon cancer has a relatively good prognosis, $20 \%$ - $25 \%$ patients eventually die of recurrence or distant metastasis, thus suggesting that adjuvant treatment is still essential in stage IIA colon cancer. Investigating the standard for selection of the candidates eligible to receive ACT in stage IIA is of utmost importance [18].

Before 2018, all RCTs on adjuvant CT in stage II colon cancer have focused on a mixed group of stage II and stage III diseases. In 2018, SACURA trial, which was the first RCT from Japan, the focus was on adjuvant CT in stage II colon cancer [13]. In this large RCT, survival benefit of ACT in high-risk stage II colon cancer was not demonstrated. Poorly differentiated histology was associated with higher risk of recurrence after the receipt of adjuvant chemotherapy. Beyond that, poorly differentiated histology showed no impact on RFS in stage II patients and was listed as a weakness in the definition of "high-risk" stage II colon cancer.

In our study, however, analyses in SEER cohort showed that poorly differentiated or undifferentiated tumor grade without ACT was associated with $14.2 \%$ increased risk of cancer-specific mortality compared to well/moderately differentiated tumor grade without ACT, while poorly differentiated or undifferentiated tumor grade without ACT presented $21.5 \%$ increased risk of cancer-specific mortality compared to after receiving ACT. Also, in FUSCC cohort, well/moderately differentiated tumor grade showed obviously better DFS compared to poorly differentiated or undifferentiated tumor grade, and poorly differentiated or undifferentiated tumor grade with ACT revealed obviously better DFS, DMFS and RFS compared to without receiving ACT. Moreover, DFS benefit offered by ACT receipt in poorly differentiated stage IIA colon cancer of FUSCC cohort was more obvious than CSS benefit in SEER cohort. Although the DFS and RFS difference in FUSCC was not statistically significant, which could result from the small sample size and short follow-up time, they also indicated that ACT receipt in poorly differentiated or undifferentiated stage II stage IIA colon cancer could not only improve the survival but also decrease tumor recurrence and distant metastasis, thus improving the life quality of patients.

Since stage IIB and IIC were not included in this study, we could not reject the results in stage II colon cancer from SACURA trial; nonetheless, our study demonstrated the poor prognosis of poorly differentiated tumor grade and supported the routine use of ACT in poorly differentiated stage IIA colon cancer. We assume one reason that SACURA trial did not show any efficacy of ACT in stage II disease with T4 or poorly differentiated tumor grade, because its treatment was based on a single oral chemotherapy drug, i.e. 1-year oral administration of tegafur-uracil. A large population-based retrospective study from the USA indicated that administration of ACT had more survival benefit in well/moderately differentiated stage II colon cancer than in poorly differentiated or undifferentiated stage II disease [11]. This study, coupled with the SACURA trial, did not exclusively focus on stage IIA colon cancer and their study cohorts were mixed with stage IIB (T4aN0M0) and IIC (T4bNOM0) colon cancers, which might have led to the inconsistent findings with our study.

The main strength of this study is that, to the best of our knowledge, this is the first large population-based study that focused on the efficacy of ACT in poorly differentiated stage IIA colon cancer, which demonstrated the efficacy of ACT in poorly differentiated or undifferentiated stage IIA colon cancer, thus supporting the routine use of ACT in poorly differentiated stage IIA disease in clinical practice.

Nonetheless, this study has some limitations that need to be pointed out. First, the present study did not include some prognostic factors of colon cancer. Nowadays, molecular biomarkers that could affect the prognosis of stage IIA colon cancer such as microsatellite instability (MSI), BRAF mutation, (carcinoembryonic antigen) and CEA level that have been extensively studied, were not included into our analyses, which might lead to bias to some extent [19-21]. Second, it was not possible to differentiate the type of CT, preoperative CT or postoperative CT in SEER database. Yet, as the preoperative CT is not the standard treatment for stage IIA disease, we could cautiously describe the "patient had chemotherapy" in "chemotherapy recode" variable as "ACT" receipt. 
Then, the regimens of adjuvant chemotherapy were also not addressed in SEER database. Finally, the statistical power of this current study was limited especially in FUSCC cohort with small sample size $(n=237)$ and short follow-up time ( $n=37$ months), causing all the differences in tumor grade and adjuvant chemotherapy were not significant. Though this study was a large population-based one in general, two cohorts in it were both retrospective rather than prospective, this approach might introduce unaccounted biases and the results should be interpreted with caution, and our conclusions need to be validated in other cohorts, especially in large RCTs.

In conclusion, poorly differentiated tumor grade showed poor prognosis in stage IIA colon cancer. As the first study, our results showed that stage IIA patients with poorly differentiated tumor grade who received ACT had better CSS and DFS. Our study provided a strong evidence to support the use of ACT in stage IIA disease with poorly differentiated tumor grade.

\section{Supplementary Material}

Supplementary figure and table.

http://www.jcancer.org/v10p1209s1.pdf

\section{Acknowledgements}

This research was supported by the National Science Foundation of China (No. 81702353 and 81772599) and Shanghai Municipal Natural Science Foundation (17ZR1406400). The funders had no role in the study design, data collection and analysis, decision to publish, or preparation of the manuscript.

\section{Ethics statement}

The study was approved by the Ethical Committee and Institutional Review Board of the Fudan University Shanghai Cancer Center. The data did not include the use of human subjects or personal identifying information and no informed consent was required for this study.

\section{Competing Interests}

The authors have declared that no competing interest exists.

\section{References}

1. Siegel RL, Miller KD, Fedewa SA, Ahnen DJ, Meester RG, Barzi A, et al Colorectal cancer statistics, 2017. Ca Cancer J Clin 2017; 67: 104-17.

2. Jessup JM, Mcginnis LS, Jr SG, Menck HR, Winchester DP. The National Cancer Data Base. Report on colon cancer. Cancer 1996; 78: 918.

3. O'Connell JB, Maggard MA, Ko CY. Colon cancer survival rates with the new American Joint Committee on Cancer sixth edition staging. Journal of the National Cancer Institute 2004; 96: 1420.

4. André T, Boni C, Mounedjiboudiaf L, Navarro M, Tabernero J, Hickish T, et al. Oxaliplatin, fluorouracil, and leucovorin as adjuvant treatment for colon cancer. The New England Journal of Medicine 2004; 350: 2343-51.
5. Gray R, Barnwell J, Mcconkey C, Hills RK, Williams NS, Kerr DJ. Adjuvant chemotherapy versus observation in patients with colorectal cancer: a randomised study. Lancet 2007; 370: 2020-9.

6. Sargent D, Sobrero A, Grothey A, O'Connell MJ, Buyse M, Andre T, et al. Evidence for cure by adjuvant therapy in colon cancer: observations based on individual patient data from 20,898 patients on 18 randomized trials. Journal of Clinical Oncology 2009; 27: 872-7.

7. Rd BA, Schrag D, Somerfield MR, Cohen AM, Figueredo AT, Flynn PJ, et al. American Society of Clinical Oncology recommendations on adjuvant chemotherapy for stage II colon cancer. Journal of Clinical Oncology 2004; 22: 3408 .

8. Labianca R, Nordlinger B, Beretta GD, Mosconi S, Mandalà M, Cervantes A, et al. Early colon cancer: ESMO Clinical Practice Guidelines for diagnosis, treatment and follow-up. Annals of Oncology 2013; 24 Suppl 6: vi64.

9. Babaei M, Balavarca Y, Jansen L, Lemmens V, van Erning FN, van Eycken L, et al. Administration of adjuvant chemotherapy for stage II-III colon cancer patients: An European population-based study. International journal of cancer 2018; 142: 1480-9.

10. Babcock BD, Aljehani MA, Jabo B, Choi AH, Morgan JW, Selleck MJ, et al. High-Risk Stage II Colon Cancer: Not All Risks Are Created Equal. Annals of surgical oncology 2018; 25: 1980-5.

11. Casadaban L, Rauscher G, Aklilu M, Villenes D, Freels S, Maker AV. Adjuvant chemotherapy is associated with improved survival in patients with stage II colon cancer. Cancer 2016; 122: 3277-87.

12. Kim MK, Won DD, Park SM, Kim T, Kim SR, Oh ST, et al. Effect of Adjuvant Chemotherapy on Stage II Colon Cancer: Analysis of Korean National Data. Cancer research and treatment. 2017; [Epub ahead of print].

13. Matsuda C, Ishiguro M, Teramukai S, Kajiwara Y, Fujii S, Kinugasa Y, et al. A randomised-controlled trial of 1-year adjuvant chemotherapy with oral tegafur-uracil versus surgery alone in stage II colon cancer: SACURA trial. European Journal of Cancer 2018; 96: 54-63.

14. O'Connor ES, Greenblatt DY, Loconte NK, Gangnon RE, Liou JI, Heise CP, et al. Adjuvant chemotherapy for stage II colon cancer with poor prognostic features. Journal of Clinical Oncology 2011; 29: 3381-8.

15. Verhoeff SR, van Erning FN, Lemmens VE, de Wilt JH, Pruijt JF. Adjuvant chemotherapy is not associated with improved survival for all high risk factors in stage II colon cancer. International Journal of Cancer Journal International Du Cancer 2016; 139: 187-93.

16. Kumar A, Kennecke HF, Renouf DJ, Lim HJ, Gill S, Woods R, et al. Adjuvant chemotherapy use and outcomes of patients with high-risk versus low-risk stage II colon cancer. Cancer 2015; 121: 527-34.

17. Babaei M, Balavarca $Y$, Jansen L, Lemmens V, van Erning FN, van Eycken L, et al. Administration of adjuvant chemotherapy for stage II-III colon cancer patients: An European population-based study. International journal of cancer 2018; 142: 1480-9.

18. Ochs AM, Wong L, Kakani V, Neerukonda S, Gorske J, Rao A, et al. Expression of Vascular Endothelial Growth Factor and HER2/ in Stage II Colon Cancer and Correlation with Survival. Clinical Colorectal Cancer 2005; 4: $262-7$.

19. Lochhead P, Kuchiba A, Yu I, Liao X, Mai Y, Nishihara R, et al. Microsatellite Instability and BRAF Mutation Testing in Colorectal Cancer Prognostication. Journal of the National Cancer Institute 2013; 105: 1151.

20. Staab HI, Anderer FA, Brummendorf T, Fischer R. Prognostic significance of preoperative carcinoembryonic antigen in stomach and colorectal cancer. Cancer Detection \& Prevention 1983; 6: 149.

21. Thirunavukarasu P, Sukumar S, Sathaiah M, Mahan M, Pragatheeshwar KD, Pingpank JF, et al. C-stage in Colon Cancer: Implications of Carcinoembryonic Antigen Biomarker in Staging, Prognosis, and Management. J Natl Cancer Inst 2011; 103: 689-97. 